\title{
TRADUCÃO E ADAPTAÇÃO TRANSCULTURAL DA SICKLE CELL DISEASE HEALTH-RELATED STIGMA SCALE PARA O CONTEXTO BRASILEIRO
}

\author{
TRANSLATION AND TRANSCULTURAL ADAPTATION \\ OF SICKLE CELL DISEASE HEALTH-RELATED \\ STIGMA SCALE FOR THE BRAZILIAN CONTEXT
}

\section{TRADUCCIÓN Y ADAPTACIÓN TRANSCULTURAL DE LA SICKLE CELL DISEASE HEALTH-RELATED STIGMA SCALE PARA EL CONTEXTO BRASILEÑO}

\author{
Sheila Santa Barbara Cerqueira ${ }^{1}$ \\ Luana Santana Brito ${ }^{2}$ \\ Katia Santana Freitas ${ }^{3}$ \\ Coretta Melissa Jenerette ${ }^{4}$ \\ Evanilda Souza de Santana Carvalho ${ }^{5}$
}

Como citar este artigo: Cerqueira SSB, Brito LS, Freitas KS, Jenerette CM, Carvalho ESS. Tradução e adaptação transcultural da Sickle Cell Disease Health-Related Stigma Scale para o contexto brasileiro. Rev baiana enferm. 2019;33:e34572.

Objetivo: descrever os procedimentos aplicados no processo de adaptação transcultural e validação de conteúdo do instrumento Sickle Cell Disease Health-Related Stigma Scale para o contexto brasileiro. Método: estudo metodológico, que realizou equivalência conceitual e de itens, equivalência semântica e equivalência operacional. O instrumento, com 40 itens subdividido em 4 subescalas, foi avaliado por um comitê de 14 especialistas e público-alvo de 30 pessoas com doença falciforme, no estado da Bahia, Brasil. Resultado: na avaliação total, o instrumento apresentou IVC de 0,80 e 0,73 para pertinência e clareza, respectivamente. Todos os itens com IVC inferiores a 0,80 foram reavaliados pelos juízes e realizadas adequações. Não foram retirados ou acrescidos itens ao instrumento adaptado e a versão final foi nomeada Sickle Cell Disease Health-Related Stigma Scale-Br. Conclusão: a versão adaptada do instrumento está adequada ao contexto brasileiro e traz contribuições para a Enfermagem no enfrentamento e na superação do estigma em saúde.

Descritores: Anemia Falciforme. Estigma Social. Doença Crônica. Discriminação Social. Estudos de Validação.

Objective: to describe the procedures applied in the process of transcultural adaptation and validation of the content of the instrument Sickle Cell Disease Health-Related Stigma Scale for the Brazilian context. Method: methodological study, which held conceptual and item equivalence, semantic equivalence and operational equivalence. The instrument, with 40 items divided into 4 subscales was assessed by a committee of 14 experts and 30 people with sickle cell disease in the state of Bahia, Brazil. Results: in the overall assessment, the instrument presented CVI of 0.80 and 0.73 for relevance and clarity, respectively. All items with CVI below 0.80 were reassessed by judges and readjusted.

\footnotetext{
Enfermeira. Mestre em Saúde Coletiva. Universidade Estadual de Feira de Santana. sheilinhabio@yahoo.com.br. https://orcid.org/0000-0002-3557-7200 Enfermeira. Universidade Estadual de Feira de Santana. Feira de Santana, Bahia, Brasil. https://orcid.org/0000-0002-7|88-54972

Enfermeira. Doutora em Enfermagem. Professora da Universidade Estadual de Feira de Santana. Feira de Santana, Bahia, Brasil. https://orcid.org/0000-0002-049 I-6759

Enfermeira. Doutora em Enfermagem. Professora da School of Nursing, University of North Carolina at Chapel Hill. Chapel Hill, North Carolina, USA. https://orcid. org/0000-0002-985 I-4768

Enfermeira. Doutora em Enfermagem. Professora da Universidade Estadual de Feira de Santana. Feira de Santana, Bahia, Brasil. https://orcid.org/0000-0003-4564-0768
} 
There were no added or removed items in relation to the adapted instrument and the final version was named Sickle Cell Disease Health-Related Stigma Scale-Br. Conclusion: the adapted version of the instrument is appropriate to the Brazilian context and brings contributions for nursing in facing and overcoming the stigma in bealth.

Descriptors: Anemia, Sickle Cell. Social Stigma. Chronic Disease. Social Discrimination. Validation Studies.

Objetivo: describir los procedimientos aplicados en el proceso de adaptación transcultural y validación del contenido del instrumento Sickle Cell Disease Health-Related Stigma Scale para el contexto brasileño. Método: estudio metodológico, que realizó la equivalencia conceptual y de elementos, la equivalencia semántica y la equivalencia operacional. El instrumento, con 40 elementos divididos en 4 sub-escalas, fue evaluado por un comité de 14 expertos y 30 personas con enfermedad de células falciformes en el estado de Bahia, Brasil. Resultados: em la evaluación global, el instrumento presentó CVI de 0,80 y 0,73 para la relevancia y claridad, respectivamente. Todos los elementos con CVI por debajo de 0,80 fueron reevaluados por jueces y reajustados. No se eliminaron o agregaron elementos para el instrumento adaptado y la versión final fue nombrada Sickle Cell Disease Health-Related Stigma Scale-Br. Conclusión: la versión adaptada del instrumento es apropiada al contexto brasileño y aporta contribuciones a la enfermería para afrontar y vencer el estigma en la salud.

Descriptores: Anemia de Células Falciformes. Estigma Social. Enfermedad Crónica. La Discriminación Social. Estudios de Validación.

\section{Introdução}

A Doença Falciforme (DF) é hereditária e muito comum no mundo. Encontra-se distribuída em todos os continentes e estima-se que, no Brasil, existem entre 25 a 30 mil pessoas vivendo com a doença. A cada ano, 3.500 novos casos são registrados. A expectativa de vida média é de 45 anos, e acomete majoritariamente pessoas afrodescendentes ${ }^{(1)}$.

As complicações da DF atingem todos os sistemas orgânicos. As alterações visíveis que produzem, conferem ao adoecido uma aparência frágil $^{(2)}$. Além disso, as constantes crises álgicas, anemia grave e priapismo levam à busca frequente por serviços de emergência. Ao serem julgadas pela aparência, as pessoas com DF são constantemente confundidas com portadores de doenças infectocontagiosas. Ao demandarem analgésicos durante as crises álgicas, são identificados como drogodependentes, o que os conduz a processos de estigmatização ${ }^{(1-4)}$.

O estigma tem sido considerado uma forte desvalorização no meio social de determinadas características de indivíduos ou grupos populacionais que estão em desacordo com normas sociais, culturais e econômicas previamente estabelecidas $^{(5)}$. Exclusão social, isolamento, dificuldade de inserção no trabalho, alterações da autoestima, baixa adesão ao cuidado, depressão e outras desordens psicoemocionais são efeitos do estigma sobre a saúde de pessoas com DF documentadas na literatura ${ }^{(3,6-9)}$. Pesquisadores preocupados com esses efeitos sobre a saúde desenvolveram instrumentos que mensuram esse fenômeno em diversos grupos e situações de saúde, incluindo a $\mathrm{DF}^{(3,6)}$.

A Sickle Cell Disease Health-Related Stigma Scale (SCD-HRSS) é um instrumento que possui 40 itens distribuídos em quatro subescalas que avalia o estigma percebido por pessoas com DF na interação com o público geral, médicos, família e enfermeiros. Na medida geral do SCD-HRSS, o alfa de Cronbach foi 0,84; nas subescalas, Público $=0,73$, Médicos =0,68 e Família = 0,82 são considerados aceitáveis. A subescala de enfermeiros foi acrescida posteriormente ${ }^{(6)}$. Esse instrumento diferencia-se dos demais encontrados na literatura, por ser específico para pessoas com DF e por trazer, em suas subescalas, itens que exploram situações nas quais o estigma emerge no contexto brasileiro, conforme evidenciado em estudos qualitativos realizados no país ${ }^{(9-10)}$.

Assim, tendo em vista a ausência de instrumentos, no Brasil, que captem o fenômeno estigma em distintas interações sociais de pessoas com DF, a existência de propriedades psicométricas iniciais favoráveis dessa medida em 
instrumento original do contexto norte-americano, e a necessidade de aprofundar o conhecimento acerca desse fenômeno, o presente estudo objetivou descrever os procedimentos aplicados no processo de adaptação transcultural e validação de conteúdo do instrumento SCD-HRSS para o contexto brasileiro.

\section{Método}

Estudo do tipo metodológico realizado em um Centro de Referência Municipal a Pessoa com Doença Falciforme e em uma Associação para Pessoas com Doença Falciforme, ambas situadas no estado da Bahia, Brasil, entre outubro de 2017 e janeiro de 2018.

A SCD-HRSS foi desenvolvida nos Estados Unidos e tem como objetivo identificar o estigma percebido por pessoas com DF em distintas interações sociais. Possui 40 itens distribuídos em quatro subescalas. A primeira, refere-se ao estigma percebido pelas pessoas com DF na interação com o público geral; a segunda, na interação com os médicos; a terceira, na interação com a família; e a quarta, na interação com enfermeiros. É uma escala do tipo Likert, com seis graduações de resposta que variam de 1 (discordo totalmente) a 6 (concordo totalmente). Assim, quanto maiores os valores de resposta atribuídos aos itens, maior é o escore e consequentemente o grau de estigma percebido pelas pessoas com $\mathrm{DF}^{(6)}$.

Para adaptação transcultural da escala, foi utilizado o modelo de avaliação das equivalências conceitual e de itens, semântica e operacional proposto por Herdman, Fox-Rushby e Badia ${ }^{(11)}$, com adoção das cinco etapas recomendadas por Beaton e colaboradores ${ }^{(12)}$ para validação da equivalência semântica (tradução, síntese da tradução, retrotradução, avaliação por comitê de especialistas e pré-teste junto à população-alvo).

$\mathrm{Na} 1^{\underline{a}}$ etapa, buscou-se a Equivalência conceitual e de itens, na qual foi realizada uma revisão integrativa da literatura acerca do construto estigma, para compreender o conceito que fundamentou a teoria do instrumento original e identificar se os conceitos presentes nos itens e nas subescalas do instrumento eram pertinentes para a cultura brasileira. Avaliou-se ainda se os itens retratavam o estigma experienciado por pessoas com DF na interação com o público geral, familiares, médicos e enfermeiros.

$\mathrm{Na} 2^{\underline{a}}$ etapa, com objetivo de alcançar a Equivalência semântica, foi realizada a tradução do instrumento SCD-HRSS por dois tradutores brasileiros, um profissional de saúde com conhecimento na DF e o outro sem aproximação com a temática, ambos com fluência na língua inglesa, dando origem a duas traduções distintas, que foram chamadas de T1 e T2 ${ }^{(12-13)}$.

A síntese das traduções T1 e T2 ocorreu em reuniões e discussões. Após o consenso da equipe de pesquisadores, chegou-se à primeira versão do instrumento na língua portuguesa (T12), a qual foi submetida à Retrotradução ou Back Translation. Isto é, foi retraduzido para o idioma de origem (língua inglesa) por tradutor americano com fluência na língua portuguesa e formação linguística. Essa retradução teve o propósito de verificar se a versão traduzida refletia o mesmo conteúdo da versão original ou seria necessário realizar adaptações, dando origem à versão B1, que foi avaliada e aprovada pela autora do instrumento original. Assim, a versão B1 foi novamente traduzida para a língua portuguesa e submetida à avaliação por um grupo de especialistas (versão T12).

Para compor o comitê de juízes, obedeceu-se aos seguintes critérios: ter formação de nível superior das diversas áreas do conhecimento; atuar com as temáticas DF e estigma em saúde; ter participado de validação de instrumentos, identificados pelo currículo Lattes. Foram convidados 20 profissionais que atenderam aos critérios de inclusão.

Todos os juízes receberam, via e-mail, a carta-convite e o Termo de Consentimento Livre e Esclarecido com a apresentação do estudo e seus objetivos. Após aceite, foram enviadas instruções quanto à avaliação do instrumento em geral, e quanto à adequação dos itens da versão traduzida do instrumento em comparação com o instrumento original e as versões do instrumento original e traduzida. Estabeleceu-se o 
prazo de 15 dias para o retorno da avaliação. Responderam ao convite 14 profissionais, com formações em enfermagem, serviço social, nutrição, fisioterapia, fonoaudiologia, sociologia e pedagogia, com idades entre 24 e 49 anos, e tempo de formação variando de 2 a 27 anos. Todos atuavam no ensino, na pesquisa, na extensão e na assistência. Quanto à titulação, seis apresentavam especialização, sete mestrado e um doutorado.

Os juízes realizaram avaliação global, com enfoque na abrangência do conteúdo e sua aceitabilidade para o público-alvo brasileiro, e avaliação individual, com enfoque nos itens para os critérios clareza e pertinência/representatividade $^{(14)}$. Essa avaliação consistiu em atribuir, a cada item, uma das quatro opções de resposta: quanto a clareza $-1=$ não claro, $2=$ pouco claro, 3=claro e 4=muito claro; quanto a pertinência $-1=$ não pertinente, $2=$ pouco pertinente, $3=$ pertinente e $4=$ muito pertinente. Eles foram orientados a sugerir alterações no instrumento, caso marcassem as opções " $1=$ não pertinente", " $2=$ pouco pertinente", " $1=$ não claro" e " $2=$ pouco claro" ${ }^{(15)}$. Em seguida, foi calculado o Índice de Validade de Conteúdo (IVC). Os itens com IVC inferior a 0,80 foram reavaliados pela equipe de pesquisa, levando em consideração as sugestões dos especialistas ${ }^{(16)}$.

$\mathrm{Na}^{3}$ etapa, Equivalência Operacional, o instrumento foi submetido a pré-teste, quando a população-alvo avaliou a disposição dos itens e das graduações de resposta, formato de apresentação do instrumento, elementos visuais utilizados, tempo necessário para responder o instrumento e avaliação do modo de aplicação do instrumento, se mediante entrevista ou questionário ${ }^{(11,17)}$.

O pré-teste foi realizado entre outubro e janeiro de 2018 em um Centro de Referência e uma Associação de Pessoas com Doença Falciforme, ambas situadas na Bahia, estado de maior prevalência da DF no Brasil. A amostra foi constituída de 30 adultos que atenderam aos critérios de inclusão: ser adulto, de ambos os sexos, com DF. Por meio de entrevista individual face a face, foram aplicados questionário sociodemográfico e o SCD-HRSS, ao qual foi acrescido espaço para registro das impressões dos participantes.
As recomendações da Resolução n⿳o 466/2012 foram atendidas. O estudo foi aprovado pelo $\mathrm{Pa}$ recer n. 2.299.220 do Comitê de Ética e Pesquisa da Universidade Estadual de Feira de Santana. Todos os participantes assinaram o Termo de Consentimento Livre e Esclarecido.

\section{Resultados}

Para a Equivalência Conceitual e de Itens foi realizada ampla pesquisa na literatura. A discussão com especialistas, incluindo a autora do instrumento, levaram à apreensão dos conceitos que fundamentaram o instrumento original. Os conceitos envolvidos no instrumento em foco, que tem como origem a cultura americana, convergiram para a cultura brasileira. Assim, o SCD-HRSS foi considerado pertinente para a cultura brasileira, não requerendo a introdução de novos itens para captar facetas não avaliadas.

$\mathrm{Na}$ análise do comitê de especialistas, algumas sugestões foram incorporadas à versão síntese proposta e houve concordância de que os itens que compõem o instrumento original, representam adequadamente aspectos e conceitos que envolvem o fenômeno do estigma percebido por pessoas com DF no contexto cultural brasileiro.

Para a Equivalência Semântica, as traduções T1 e T2 foram avaliadas pelas pesquisadoras para chegar a uma versão síntese. Todos os 40 itens tiveram traduções semelhantes, sendo adotados aqueles vocábulos mais usuais no cotidiano da população-alvo brasileira.

Quanto à Abrangência do Conteúdo, os juízes consideraram adequada a relação entre as subescalas apresentadas e os 40 itens. Entretanto, sugeriram mudança na graduação da resposta, passando de seis para cinco: discordo totalmente, discordo em parte, não concordo e nem discordo, concordo em parte e concordo totalmente.

$\mathrm{Na}$ avaliação individual, oito itens tiveram IVC menor do que 0,80 para pertinência: os itens $3(0,79), 9(0,71)$ e $10(0,71)$ da primeira subescala; $2(0,79)$ e $5(50 \%)$ da segunda subescala; 6 $(0,64)$ e $9(0,57)$ da terceira subescala; e $5(0,71)$ 
da quarta subescala. Desse modo, o instrumento total apresentou IVC para pertinência de 0,80.

Quanto à avaliação da clareza, 11 itens apresentaram IVC menor do que 0,80: os itens 3 $(0,79)$ e $7(0,50)$ da primeira subescala; $1(0,79)$, $4(0,71), 5(0,79), 6(0,79), 7(0,79), 8(0,71)$ e 9 $(0,79)$ da segunda subescala; e $4(0,79)$ e $7(0,71)$ da terceira subescala. A quarta subescala não teve nenhum item com IVC para clareza menor que 0,80. O instrumento total apresentou IVC para clareza de 0,73. A avaliação da clareza não foi satisfatória. Assim, após avaliação dos especialistas, os itens que apresentaram concordância inferior a $80 \%$ tiveram a sua redação reescrita, sendo acrescentados e/ou suprimidos alguns termos, para que se tornasse compreensível para a população-alvo, e foram submetidos novamente à apreciação dos juízes para aprovação.

Os Quadros 1 e 2 mostram o IVC menor que 0,80 da versão em português do instrumento antes e após avaliação do comitê de especialistas, com as considerações feitas em cada item. No Quadro 1, são apresentadas alterações recomendadas às subescalas 1 e 2 , as quais exploram o estigma no público geral e na interação com médicos.

Quadro 1 - Índice da Validade de Conteúdo da pertinência, clareza e versão em português após avaliação do comitê de juízes das subescalas 1 e 2

(continua)

\begin{tabular}{|c|c|c|c|}
\hline $\begin{array}{l}\text { Questão (item) antes das } \\
\text { considerações dos juizes }\end{array}$ & Pertinência & Clareza & $\begin{array}{c}\text { Questão (item) após } \\
\text { considerações dos juízes }\end{array}$ \\
\hline \multicolumn{4}{|c|}{ SUBESCALA 1 - Público geral } \\
\hline $\begin{array}{l}\text { 3. As pessoas são compreensivas } \\
\text { quando escutam eu falar sobre a } \\
\text { minha condição de dor. }\end{array}$ & 0,79 & 0,79 & $\begin{array}{l}\text { As pessoas entendem quando eu } \\
\text { falo sobre a minha dor. }\end{array}$ \\
\hline $\begin{array}{l}\text { 7. As pessoas pensam e } \\
\text { menosprezam alguém que é } \\
\text { incapaz de trabalhar por causa da } \\
\text { doença falciforme. }\end{array}$ & - & 0,50 & $\begin{array}{l}\text { As pessoas pensam que alguém } \\
\text { com doença falciforme é } \\
\text { incapaz de trabalhar. }\end{array}$ \\
\hline $\begin{array}{l}\text { 9. As pessoas pensam que } \\
\text { alguém que toma medicamentos } \\
\text { receitados para dor de forma } \\
\text { regular é um "viciado em drogas". }\end{array}$ & 0,71 & - & $\begin{array}{l}\text { As pessoas pensam que quem } \\
\text { sempre toma remédios para dor } \\
\text { é um viciado em medicamentos. }\end{array}$ \\
\hline \multicolumn{4}{|c|}{ SUBESCALA 2-Médicos } \\
\hline $\begin{array}{l}\text { 1. A maioria dos médicos acredita } \\
\text { que há uma causa física real para } \\
\text { dor falciforme. }\end{array}$ & - & 0,79 & $\begin{array}{l}\text { A maioria dos médicos acredita } \\
\text { que existe uma causa verdadeira } \\
\text { para dor falciforme. }\end{array}$ \\
\hline $\begin{array}{l}\text { 2. Os médicos acham que as } \\
\text { pessoas com doença falciforme } \\
\text { exageram sua dor. }\end{array}$ & 0,79 & - & $\begin{array}{l}\text { Os médicos acham que as } \\
\text { pessoas com doença falciforme } \\
\text { exageram quando falam da sua } \\
\text { dor. }\end{array}$ \\
\hline $\begin{array}{l}\text { 4. Os médicos acham que a dor } \\
\text { falciforme é, na maior parte, um } \\
\text { problema mental ou emocional. }\end{array}$ & - & 0,71 & $\begin{array}{l}\text { Os médicos acham que na } \\
\text { maioria das vezes a dor das } \\
\text { pessoas com doença falciforme } \\
\text { é um problema mental ou } \\
\text { emocional. }\end{array}$ \\
\hline $\begin{array}{l}\text { 5. A maioria dos médicos acha } \\
\text { que as pessoas com doença } \\
\text { falciforme usam medicação para a } \\
\text { dor de forma apropriada. }\end{array}$ & 0,50 & 0,79 & $\begin{array}{l}\text { A maioria dos médicos acha } \\
\text { que as pessoas com doença } \\
\text { falciforme usam medicação para } \\
\text { a dor de forma correta. }\end{array}$ \\
\hline $\begin{array}{l}\text { 6. A maioria dos médicos acha } \\
\text { que as pessoas com doença } \\
\text { falciforme reclamam sobre sua } \\
\text { doença tanto quanto as pessoas } \\
\text { com outras condições médicas. }\end{array}$ & - & 0,79 & $\begin{array}{l}\text { A maioria dos médicos acha } \\
\text { que as pessoas com doença } \\
\text { falciforme reclamam mais do } \\
\text { que outras pessoas com outros } \\
\text { problemas de saúde. }\end{array}$ \\
\hline
\end{tabular}


Quadro 1 - Índice da Validade de Conteúdo da pertinência, clareza e versão em português após avaliação do comitê de juízes das subescalas 1 e 2

\begin{tabular}{|l|c|c|l|}
\hline $\begin{array}{l}\text { Questão (item) antes das } \\
\text { considerações dos juizes }\end{array}$ & Pertinência & Clareza & \multicolumn{1}{c|}{$\begin{array}{c}\text { Questão (item) após } \\
\text { considerações dos juízes }\end{array}$} \\
\hline \multicolumn{2}{|c|}{ SUBESCALA $\mathbf{~ - ~ M e ́ d i c o s ~}$} \\
\hline $\begin{array}{l}\text { 7. Muitos médicos acreditam que } \\
\text { as pessoas com doença falciforme } \\
\text { poderiam ser mais fisicamente } \\
\text { ativas, se quisessem. }\end{array}$ & - & 0,79 & $\begin{array}{l}\text { Muitos médicos acreditam } \\
\text { que as pessoas com doença } \\
\text { falciforme poderiam ser mais } \\
\text { ativas, se quisessem. }\end{array}$ \\
\hline $\begin{array}{l}\text { 8. Muitos médicos acham que as } \\
\text { pessoas com doença falciforme } \\
\text { são menos emocionalmente } \\
\text { estáveis do que as pessoas com } \\
\text { outros problemas de saúde. }\end{array}$ & - & 0,71 & $\begin{array}{l}\text { Muitos médicos acham que as } \\
\text { pessoas com doença falciforme } \\
\text { têm mais problemas emocionais } \\
\text { do que aqueles com outros } \\
\text { problemas de saúde. }\end{array}$ \\
\hline $\begin{array}{l}\text { 9. Muitos médicos acham que as } \\
\text { pessoas com dor falciforme são } \\
\text { "viciadas em drogas". }\end{array}$ & - & $\begin{array}{l}\text { Muitos médicos acham que as } \\
\text { pessoas com doença falciforme } \\
\text { que tomam remédio para dor } \\
\text { são "viciadas em medicamentos". }\end{array}$ \\
\hline
\end{tabular}

Fonte: Elaboração própria.

No Quadro 2, são apresentadas alterações em quatro itens da subescala 3 e um item da subescala 4 , as quais buscam apreender o estigma percebido nas interações entre pessoas com DF na família e com enfermeiros.

Quadro 2 - Versão síntese em português T12, Índice da Validade de Conteúdo da pertinência, clareza e versão em português após avaliação do comitê de juízes das subescalas 3 e 4

\begin{tabular}{|c|c|c|c|}
\hline $\begin{array}{l}\text { Questão (item) antes das } \\
\text { considerações dos juízes }\end{array}$ & Pertinência & Clareza & $\begin{array}{c}\text { Questão (item) após } \\
\text { considerações dos juízes }\end{array}$ \\
\hline \multicolumn{4}{|c|}{ SUBESCALA 3 - Família } \\
\hline $\begin{array}{l}\text { 4. Minha família entende que eu posso } \\
\text { usar apenas a quantidade de medicação } \\
\text { para dor que está prescrita. }\end{array}$ & - & 0,79 & $\begin{array}{l}\text { Minha família entende que } \\
\text { eu posso usar apenas a } \\
\text { quantidade de medicação } \\
\text { para dor que está na } \\
\text { receita. }\end{array}$ \\
\hline $\begin{array}{l}\text { 6. Minha família pensa que, por tomar } \\
\text { medicação para a dor regularmente, eu } \\
\text { me tornei um "viciado em drogas". }\end{array}$ & 0,64 & - & $\begin{array}{l}\text { Minha família pensa que, } \\
\text { por tomar medicação para } \\
\text { a dor regularmente, eu } \\
\text { me tornei um "viciado em } \\
\text { medicamentos". }\end{array}$ \\
\hline $\begin{array}{l}\text { 7. Minha família entende que doença } \\
\text { falciforme é uma condição médica real. }\end{array}$ & - & 0,71 & $\begin{array}{l}\text { Minha família entende } \\
\text { que doença falciforme é } \\
\text { um problema de saúde } \\
\text { verdadeiro. }\end{array}$ \\
\hline $\begin{array}{l}\text { 9. Minha família pensa que a dor } \\
\text { falciforme é mais um problema mental } \\
\text { ou emocional do que um problema físico. }\end{array}$ & 0,57 & - & $\begin{array}{l}\text { Minha família pensa que } \\
\text { a minha dor é mais um } \\
\text { problema mental ou } \\
\text { emocional do que um } \\
\text { problema físico. }\end{array}$ \\
\hline \multicolumn{4}{|c|}{ SUBESCALA $4-$ Enfermeiros } \\
\hline $\begin{array}{l}\text { 5. A maioria dos enfermeiros acha que } \\
\text { as pessoas com doença falciforme usam } \\
\text { medicação para dor de forma apropriada. }\end{array}$ & 0,71 & - & $\begin{array}{l}\text { A maioria dos enfermeiros } \\
\text { acha que as pessoas com } \\
\text { doença falciforme usam } \\
\text { medicação para dor de } \\
\text { forma correta. }\end{array}$ \\
\hline
\end{tabular}


Na fase do "pré-teste", o instrumento foi aplicado junto à população-alvo, após mudanças no instrumento de base com as considerações dos especialistas. Nessa fase, foram observados consensos, divergências e dificuldades de compreensão dos itens sinalizados por adultos com DF.

Os participantes sugeriram modificações na escrita dos itens 1 e 5 das subescalas 2 e 4, propondo substituição do termo "causa física real" por "causa verdadeira"; no item 4, sugeriam substituir o termo "apropriada" por "correta". Alegaram que os termos podiam fazer entender que se referia à "causa" da fisiopatologia da doença, conhecimento médico ou origem da doença na população. As sugestões foram discutidas, acatadas e a escrita dos itens foi revisada.

No item 5, das subescalas 2 e 5, os participantes sugeriram colocar o enunciado da questão na forma negativa, para tornar mais compreensível no momento de responder. A sugestão foi acatada e o enunciado foi assim reescrito: "A maioria dos médicos acha que as pessoas com doença falciforme não usam medicação para a dor de forma correta" e "A maioria dos enfermeiros acha que as pessoas com doença falciforme não usam medicação para a dor de forma correta."

Observou-se que os participantes com menor nível de escolaridade apresentaram dificuldades de compreensão da escala Likert, sendo necessário que a pesquisadora repetisse algumas perguntas, para que o conteúdo do item fosse compreendido.

Quanto à equivalência operacional do instrumento, os participantes observaram a disposição dos itens e sua estética e sugeriram redução das opções da escala Likert para cinco respostas e a organização da escala em forma de livreto, com uma subescala em cada página, ou sua aplicação de forma fracionada. A duração da aplicação do instrumento a cada indivíduo variou de 15 a 30 minutos e contou com o auxílio da pesquisadora. Esta, ao final, indicou o uso de aplicação supervisionada. O instrumento foi aceito pelo público-alvo, que reforçou a importância de ser ouvido. Durante a leitura dos itens, muitos se sentiram motivados a narrar suas experiências de forma mais aprofundada.

\section{Discussão}

No contexto brasileiro, inexistem instrumentos para mensuração do estigma percebido na DF. A adaptação transcultural apresenta vantagens consideráveis em relação à criação de um novo instrumento, pois seus itens já foram validados em outras culturas, no que se refere à validade de conteúdo e qualidades psicométricas, o que poupa tempo e trabalho do pesquisador, além de possibilitar a comparação dos dados obtidos em diferentes culturas ${ }^{(12,18-19)}$.

Esse é um processo que abarca não somente a tradução para o novo idioma, mas também atenta para as questões culturais, para posterior aplicação no novo contexto. Atender à equivalência entre a fonte original e a população-alvo requer a utilização de metodologia rigorosa ${ }^{(12)}$. Contar com profissionais que conheçam linguística e com um comitê de juízes multidisciplinar, com amplo conhecimento sobre a DF, foi essencial para assegurar a qualidade e a validade de conteúdo durante o processo de adaptação.

A construção do instrumento original foi pautada no conceito sobre estigma relacionado à saúde, o qual compreende a co-ocorrência de componentes - rotulagem, estereótipos, perda de status, discriminação, desvalorização, julgamento ou desqualificação social de indivíduos ou grupos - tomando como base uma condição relacionada à saúde ${ }^{(6,20)}$.

Iniciado pela revisão da teoria do estigma e das características do fenômeno adotadas no instrumento original, o processo de tradução e adaptação cultural da SCD-HRSS seguiu todas as etapas de modo sistematizado e criterioso, condição requerida para assegurar sua validade. Durante a avaliação das versões traduzidas e sintetizadas, foram aplicadas tanto estratégias qualitativas, com apreensão de opinião individual dos especialistas, quanto quantitativas, com aplicação de medidas estatísticas, ao mensurar o grau de concordância entre esses ${ }^{(15)}$.

O público-alvo da fase pré-teste do instrumento foi composto por 30 indivíduos. A literatura recomenda que essa etapa envolva entre 30-40 participantes entrevistados individualmente 
sobre o entendimento de itens, palavras e respostas, assegurando a maior abrangência de opiniões e a qualidade do instrumento para as futuras provas psicométricas ${ }^{(12,14)}$. A coleta de dados mediante entrevistas favoreceu a análise crítica detalhada do instrumento, na medida em que possibilitou apreender aspectos da expressão dos participantes, como linguagem falada e escrita, linguagem corporal, emoções, gestos e olhares, conforme recomendado pela Teoria Sistêmico-Funcional ${ }^{(14)}$.

$\mathrm{Na}$ análise individual dos itens do instrumento, verificou-se a pertinência do conteúdo quanto ao fenômeno estudado, entretanto foi necessária a adequação de algumas palavras, substituição de termos e expressões por sinônimos, além de adequações de tempos verbais. Essas alterações já são esperadas, pois visam manter a equivalência semântica, uma vez que particularidades culturais, crenças, religião, valores éticos e morais de um determinado grupo populacional podem influenciar na compreensão e operacionalização do instrumento e inviabilizar sua aplicabilidade, se não for adequado ao contexto em que será aplicado ${ }^{(17,21-22)}$.

Embora a equipe de pesquisa tenha buscado participantes de diversos níveis de letramento, as dificuldades de compreensão observadas no público-alvo foram decisivas para as adequações na linguagem do instrumento adaptado, para melhor compreensão desse grupo no contexto brasileiro ${ }^{(9-10,23)}$.

Estudo desenvolvido com mulheres demonstrou que "[...] mesmo a escala sendo aplicada pelas pesquisadoras surgiram dificuldades quanto à compreensão de alguns itens" ${ }^{, 24: 302)}$. No presente estudo, observou-se que indivíduos da população-alvo com menor escolaridade demandaram maior tempo para responder e apresentaram limitações para sugerir adequações de linguagem e reformulações de itens do instrumento. Essa dificuldade não foi encontrada no estudo original, no qual todos os participantes responderam ao instrumento sozinhos ${ }^{(6)}$.

Devido à diversidade de manifestações que podem ser expressas no corpo, as pessoas com DF estão vulneráveis a sofrer discriminação e serem estigmatizadas em função da diferença e de incapacidades causadas pela doença em seus corpos nos diversos contextos sociais ${ }^{(4,9-10)}$. Assim, a organização da SCD-HRSS em subescalas permite conhecer o estigma percebido pelos adoecidos em diferentes grupos de interação, revelando aspectos passíveis de intervenção dirigida para o enfrentamento do estigma em cada um desses grupos.

Nos serviços de saúde, o estigma percebido nas interações com profissionais pode estar associado às questões raciais, à invisibilidade da doença na sociedade, ao desconhecimento dos sinais e sintomas clínicos pelos profissionais de saúde e por ser considerada uma doença de grupos desfavorecidos, como os de pessoas negras, com baixa escolaridade e baixo poder socioeconômico ${ }^{(9-25)}$. Nesse sentido, a validade de conteúdo permite alcançar uma versão de instrumento que seja capaz de captar essas nuances da experiência no contexto em que será aplicado. O SCD-HRSS-Br alcançou índice de concordância entre os juízes, que confirmaram que o estigma em pessoas com DF no contexto brasileiro é explorado adequadamente pelo instrumento.

Dentre os itens da SCD-HRSS-Br, os juízes concordaram que muitos exploram a discriminação que emerge nos momentos de dor, fundamentando suas opiniões em estudos que mostram que a pessoa com DF apresenta frequentes crises dolorosas. Estas influenciam a qualidade e as expectativas das interações estabelecidas entre os adoecidos e demais sujeitos da sociedade. O instrumento permite explorar a existência do descrédito, atribuição de culpa, aplicação de rótulo, atitudes de afastamento e discriminação diante das narrativas de dor ${ }^{(9,25)}$.

A importância dos eventos de crise dolorosa para ampliação do estigma em pessoas com DF foi verificada no estudo original, em que mais hospitalizações ao ano, para tratar crises álgicas, evidenciou maior estigma nas interações com os médicos ${ }^{(6)}$.

Juízes e equipe de pesquisa consideraram que, apesar de o instrumento SCD-HRSS-Br ter abarcado características do estigma, poderá vir a sofrer modificações no futuro, pois um 
instrumento pode ser aprimorado para acompanhar as mudanças do fenômeno que pretende mensurar e do contexto em que é aplicado ${ }^{(17)}$.

No presente estudo, a autora do instrumento original teve participação direta em todo o processo de adaptacao transcultural da SCD-HRSS, aspecto que agrega valor e certifica a segurança e a qualidade do produto final ${ }^{(15)}$.

A SCD-HRSS-Br poderá apoiar estudos e avaliações antes e após aplicação de planos de enfrentamento do estigma em saúde, permitindo comparar os efeitos sobre as dimensões da vida que costumam ser afetadas nos indivíduos estigmatizados, como fisiológica, psicológica e de bem-estar social ${ }^{(6,20)}$, mediante aplicação em conjunto com outros instrumentos.

As subescalas destinadas a avaliar o estigma na interação com os diversos públicos poderão produzir conhecimento específico sobre atitudes e práticas discriminatórias que ocorrem nos contextos de cuidado e subsidiar planos de medidas para sua superação, envolvendo tanto os currículos formadores quanto as qualificações de educação permanente e campanhas de divulgação sobre a doença ${ }^{(1-2)}$.

Como limitação deste estudo, cita-se a ausência de estudos nacionais sobre adaptação transcultural e confiabilidade de instrumentos para o fenômeno estigma, o que dificultou possíveis comparações. A escala original foi amplamente utilizada no contexto de origem, mas foi a primeira exposição a um contexto e cultura diferentes.

\section{Conclusão}

A avaliação do instrumento pelos especialistas e pela população-alvo permitiu adequações de conteúdo na SCD-HRSS, sendo possível afirmar que está adequada ao contexto brasileiro e apresenta validade de conteúdo para ser aplicado, além de trazer contribuições para a Enfermagem no enfrentamento e na superação do estigma em saúde.

Profissionais de saúde e pesquisadores poderão acessar um instrumento válido para analisar as experiências de estigma das pessoas com DF em diferentes relações sociais, com implicações diretas para a saúde coletiva, que pode atuar na superação do estigma em saúde por meio de educação em saúde e inclusão da temática nos currículos formadores. Além disso, destaca-se a contribuição do estudo para mensuração do estigma nas interações com os enfermeiros.

Esta tradução e adaptação do SCD-HRSS-Br conclui a etapa que viabiliza a futura aplicação de provas psicométricas do instrumento com vistas à sua reprodutibilidade no contexto brasileiro.

\section{Colaborações:}

1 - concepção, projeto, análise e interpretação dos dados: Sheila Santa Barbara Cerqueira;

2 - redação do artigo e revisão crítica relevante do conteúdo intelectual: Sheila Santa Barbara Cerqueira, Luana Santana Brito, Katia Santana Freitas e Evanilda Souza de Santana Carvalho;

3 - aprovação final da versão a ser publicada: Sheila Santa Barbara Cerqueira, Katia Santana Freitas, Coretta Melissa Jenerette e Evanilda Souza de Santana Carvalho.

\section{Referências}

1. Soares EPB, Silva DS, Xavier ASG, Carvalho ESS, Cordeiro RC, Araújo EM. Care for people with sickle cell in the emergency room: accessing the knowledge of a multiprofissional team. Cienc Cuid Saude. 2014;13(2):278-85. DOI: 10.4025/ cienccuidsaude.v13i2.19505

2. Maia HAAS, Alvaia MA, Carneiro JM, Xavier ASG, Bessa Júnior J, Carvalho ESS. Access of men with sickle cell disease and priapism in emergency services. BrJP. 2019;2(1):20-6. DOI: http://dx.doi. org/10.5935/2595-0118.2019000

3. Bediako SM, Lanzkron S, Diener-West $\mathrm{M}$, Onojobi G, Beach MC, Haywood CJr. The measure of sickle cell stigma: initial findings from the improving patient outcomes through respect and trust study. J Health Psychol. 2016;21(5):808-20. DOI: $10.1177 / 1359105314539530$

4. Goffman E. Estigma: notas sobre a manipulação da identidade deteriorada. Tradução Nunes MBML [Internet]. Rio de Janeiro: LTC; 1975 [cited 2018 Feb 18]. Available from: http://www.aberta.senad.gov. br/medias/original/201702/20170214-114707-001. pdf 
5. Jenerette C, Brewer CA, Crandell J, Ataga KI. Preliminary validity and reliability of the Sickle Cell Disease Health-Related Stigma Scale. Issues in Ment Health Nurs. 2012;33(6):363-9. DOI: https:// doi.org/10.3109/01612840.2012.656823

6. Matthie N, Hamilton J, Wells D, Jenerette C. Perceptions of young adults with sickle cell disease concerning their disease experience. J Adv Nurs. 2016;72(6):1441-51. DOI: 10.1111/jan.12760

7. Adam SS, Flahiff CM, Kamble S, Telen MJ, Reed SD, De Castro LM. Depression, quality of life, and medical resource utilization in sickle cell disease. Blood Adv. 2017;1(23):1983-92. DOI: 10.1182/bloodadvances.2017006940

8. Adeyemo AT, Ojewunmi OO, Diaku-Akinwumi IN, Ayinde OC, Akanmu AS. Health related quality of life and perception of stigmatisation in adolescents living with sickle cell disease in nigeria: a cross sectional study. Pediatr Blood Cancer 2015;62(7):1245-51. DOI: 10.1002/pbc. 25503

9. Figueiró AVM, Ribeiro RLR. Vivência do preconceito racial e de classe na doença falciforme. Saude soc. 2017;26(1):88-99. DOI: http://dx.doi.org/10.1590/ s0104-12902017160873

10. Carvalho SC, Carvalho LC, Fernandes JG, Santos MJS. Em busca da equidade no sistema de saúde brasileiro: o caso da doença falciforme. Saude soc. 2014;23(2):711-8. DOI: http://dx.doi. org/10.1590/S0104-12902014000200029

11. Herdman M, Fox-Rushby J, Badia X. "Equivalence" and the translation and adaptation of health-related quality of life questionnaires. Qual Life Res. 1997;6(3):237-47. DOI: https://doi. org/10.1023/A:1026410721664

12. Beaton DE, Bombardier C, Guillemin F, Ferraz MB. Guidelines for the Process of Cross-Cultural Adaptation of Self-Report Measures. Spine. 2000;25(24):3186-91. DOI: http://dx.doi. org/10.1097/00007632-200012150-00014

13. Cassepp-Borges V, Balbinott MAA, Teodoro MLM. Tradução e validação de conteúdo: uma proposta para a adaptação de instrumentos. In: Pasqual L. Instrumentação psicológica: fundamentos e práticas. Porto Alegre: Artmed; 2010. p. 506-20.

14. Coluci MZO, Alexandre NMC, Milani C. Construção de instrumentos de medida na área da saúde. Ciênc saúde coletiva. 2015;20(3):925-36. DOI: http:// dx.doi.org/10.1590/1413-81232015203.04332013
15. Lino CRM, Brüggemann OM, Souza ML, Barbosa SFF, Santos EKA. The cross-cultural adaptation of research instruments, conducted by nurses in Brazil: an integrative review. Texto contexto-enferm. 2017;26(4):e1730017. DOI: http:// dx.doi.org/10.1590/0104-07072017001730017

16. Polit D, Beck C. Fundamentos de pesquisa em enfermagem: avaliação de evidências para a prática da enfermagem. 7a ed. Porto Alegre: Artmed; 2011.

17. Reichenheim ME, Moraes CL. Operationalizing the cross-cultural adaptation of epidemological measurement instruments. Rev Saúde Pública. 2007;41(4):665-73. DOI: http://dx.doi.org/10.1590/ S0034-89102006005000035

18. Guillemin F, Bombardier C, Beaton D. Cross-cultural adaptation of health-related quality of life measures: literature review and proposed guidelines. J Clin Epidemiol. 1993;46(12):1417-32. DOI: https://doi. org/10.1016/0895-4356(93)90142-N

19. Borsa JC, Damásio BF, Bandeira DR. Cross-cultural adaptation and validation of psychological instruments: some considerations. Paidéia (Ribeirão Preto). 2012;22(53):423-32. DOI: https:// dx.doi.org/10.1590/S0103-863X2012000300014

20. Link GB, Phelan JC. Conceptualizing Stigma. Annu Rev Sociol. 2001;27:363-85. DOI: https://doi. org/10.1146/annurev.soc.27.1.363

21. Sampaio PF, Moraes CL, Reichenheim M. Equivalência conceitual, de itens, semântica e operacional da versão brasileira do s-EMBU para aferição de práticas educativas parentais em adolescentes. Cad Saúde Pública. 2014;30(8):1633-8. DOI: http:// dx.doi.org/10.1590/0102-311X00036614

22. Epstein J, Santo RM, Guillemin F. A review of guidelines for cross-cultural adaptation of questionnaires could not bring out a consensus. J Clin Epidemiol [Internet]. 2015;68(4):435-41. DOI: 10.1016/j.jclinepi.2014.11.021

23. Silva RBP, Ramalho AS, Cassorla RMS. A anemia falciformecomoproblemadeSaúdePúblicanoBrasil. Rev Saúde Pública. 1993;27(1):54-8. DOI: http:// dx.doi.org/10.1590/S0034-89101993000100009

24. Fernandes ETBS, Dias ACS, Ferreira SL, Marques GCM, Pereira COJ. Cultural and reliable adaptation of the Reproductive Autonomy Scale for women in Brazil. Acta paul enferm. 2019;32(3):298-304. DOI: http://dx.doi.org/10.1590/1982-0194201900041 
Sheila Santa Barbara Cerqueira, Luana Santana Brito, Katia Santana Freitas, Coretta Melissa Jenerette, Evanilda Souza de Santana Carvalho

25. Puri Singh A, Haywood C, Beach MC, Guidera M, Lanzkron S, Valenzuela-Araujo D, et al. Improving Emergency Providers' Attitudes Toward Sickle Cell Patients in Pain. J Pain Symptom Manage. 2016;51(3):628-32. DOI: http://dx.doi.org/10.1016/ j.jpainsymman.2015.11.004
Recebido: 13 de novembro de 2019

Aprovado: 14 de novembro de 2019

Publicado: 11 de março de 2020

A Revista Baiana de Enfermagem utiliza a Licença Creative Commons - Atribuição-NãoComercial 4.0 Internacional. https://creativecommons.org/licenses/by-nc/4.0/ Este artigo é de acesso aberto distribuído sob os termos da Licença Creative Commons (CC BY-NC). Esta licença permite que outros remixem, adaptem e criem a partir do seu trabalho para fins não comerciais. Embora os novos trabalhos tenham de lhe atribuir o devido crédito e não possam ser usados para fins comerciais, os usuários não têm de licenciar esses trabalhos derivados sob os mesmos termos. 